\title{
Correction to: Safety and efficacy of nivolumab in combination with sunitinib or pazopanib in advanced or metastatic renal cell carcinoma: the CheckMate 016 study
}

\author{
Asim Amin ${ }^{1 *}$, Elizabeth R. Plimack ${ }^{2}$, Marc S. Ernstoff ${ }^{3}$, Lionel D. Lewis ${ }^{4}$, Todd M. Bauer ${ }^{5}$, David F. McDermott ${ }^{6}$, \\ Michael Carducci ${ }^{7}$, Christian Kollmannsberger ${ }^{8}$, Brian I. Rini ${ }^{9}$, Daniel Y. C. Heng ${ }^{10}$, Jennifer Knox ${ }^{11}$, Martin H. Voss ${ }^{12}$, \\ Jennifer Spratlin ${ }^{13}$, Elmer Berghorn ${ }^{14}$, Lingfeng Yang ${ }^{14}$ and Hans J. Hammers ${ }^{15}$
}

\section{Correction to: Journal for ImmunoTherapy of Cancer (2018) 6:109 \\ https://doi.org/10.1186/s40425-018-0420-0}

Following publication of the original article [1], the author reported a mistake related to a percentage. In page 5 the sentence "Two (6.1\%) patients achieved a complete response, 16 (48.5\%) achieved a partial response, 11 (33.3\%) had stable disease, one $(0.3 \%)$ had progressive disease, and in three patients (9.1\%), response was undeterminable." should be replaced with "Two (6.1\%) patients achieved a complete response, 16 (48.5\%) achieved a partial response, $11(33.3 \%)$ had stable disease, one (3.0\%) had progressive disease, and in three patients $(9.1 \%)$, response was undeterminable." (3.0\% instead of $0.3 \%)$.

The publisher apologizes for any inconvenience caused by this error.

\footnotetext{
Author details

'Immunotherapy program, Levine Cancer Institute, Carolinas HealthCare System, 1024 Morehead Medical Drive, Charlotte, NC 28204, USA. ${ }^{2}$ Division of Genitourinary Medical Oncology, Department of Hematology/Oncology, Fox Chase Cancer Center, Philadelphia, PA 19111, USA. ${ }^{3}$ Division of Oncology, Department of Medicine, Roswell Park Cancer Institute, Elm and Carlton Streets, Buffalo, NY 14203, USA. ${ }^{4}$ Department of Medicine at The Geisel School of Medicine and The Norris Cotton Cancer Center at Dartmouth-Hitchcock Medical Center, Lebanon, NH 03756, USA. ${ }^{5}$ Sarah Cannon Research Institute/Tennessee Oncology, PLLC, Nashville, TN 37203, USA. ${ }^{6}$ Department of Medicine, Beth Israel Deaconess Medical Center, Dana-Farber/Harvard Cancer Center, Boston, MA 02215, USA. ${ }^{7}$ Department of Oncology, Johns Hopkins Sidney Kimmel Comprehensive Cancer Center, Baltimore, MD 21287, USA. ${ }^{8}$ Division of Medical Oncology, British Columbia Cancer Agency, Vancouver, BC V5Z 4E6, Canada. ' 2 Lerner College of Medicine, Department of Hematology and Oncology, Cleveland Clinic Taussig Cancer
}

Institute, Cleveland, OH 44195, USA. ${ }^{10}$ Department of Oncology, Tom Baker Cancer Center, University of Calgary, Calgary, AB T2N 4N2, Canada. ${ }^{11}$ Cancer Clinical Research Unit (CCRU), Princess Margaret Cancer Centre, Toronto, ON M5G 1Z5, Canada. ${ }^{12}$ Department of Medicine, Memorial Sloan Kettering Cancer Center, New York, NY 10065, USA. ${ }^{13}$ Department of Oncology, Cross Cancer Institute, University of Alberta, Edmonton, AB T6G 1Z2, Canada. ${ }^{14}$ Oncology - Global Clinical Research, Bristol-Myers Squibb, Princeton, NJ 08541, USA. ${ }^{15}$ Department of Internal Medicine, UT Southwestern - Kidney Cancer Program, Dallas, TX 75390, USA.

Received: 8 March 2019 Accepted: 8 March 2019

Published online: 14 March 2019

\section{Reference}

1. Amin A, et al. Safety and efficacy of nivolumab in combination with sunitinib or pazopanib in advanced or metastatic renal cell carcinoma: the CheckMate 016 study. J Immunother Cancer. 2018;6:109. https://doi.org/10. 1186/s40425-018-0420-0

\footnotetext{
* Correspondence: Asim.Amin@carolinashealthcare.org

'Immunotherapy program, Levine Cancer Institute, Carolinas HealthCare

System, 1024 Morehead Medical Drive, Charlotte, NC 28204, USA

Full list of author information is available at the end of the article
}

(c) The Author(s). 2019 Open Access This article is distributed under the terms of the Creative Commons Attribution 4.0 International License (http://creativecommons.org/licenses/by/4.0/), which permits unrestricted use, distribution, and reproduction in any medium, provided you give appropriate credit to the original author(s) and the source, provide a link to the Creative Commons license, and indicate if changes were made. The Creative Commons Public Domain Dedication waiver (http://creativecommons.org/publicdomain/zero/1.0/) applies to the data made available in this article, unless otherwise stated. 


\title{
Safety and efficacy of nivolumab in combination with sunitinib or pazopanib in advanced or metastatic renal cell carcinoma: the CheckMate 016 study
}

Asim Amin ${ }^{1 *}$, Elizabeth R Plimack², Marc S Ernstoff ${ }^{3}$, Lionel D Lewis ${ }^{4}$, Todd M Bauer $^{5}$, David F McDermott ${ }^{6}$, Michael Carducci ${ }^{7}$, Christian Kollmannsberger ${ }^{8}$, Brian I Rini ${ }^{9}$, Daniel Y C Heng ${ }^{10}$, Jennifer Knox ${ }^{11}$, Martin H Voss ${ }^{12}$, Jennifer Spratlin ${ }^{13}$, Elmer Berghorn ${ }^{14}$, Lingfeng Yang ${ }^{14}$ and Hans J Hammers ${ }^{15}$

\begin{abstract}
Background: Combination treatment with immune checkpoint inhibitors and antiangiogenic drugs has shown encouraging preliminary antitumor activity across various tumor types including advanced or metastatic renal cell carcinoma (aRCC). The open-label, parallel-cohort, dose-escalation, phase I CheckMate 016 study evaluated the efficacy and safety of nivolumab in combination with antiangiogenic tyrosine kinase inhibitors or ipilimumab. Longterm outcomes from this study for the combination of nivolumab plus sunitinib or pazopanib in aRCC are presented.

Methods: Patients with aRCC received nivolumab plus either sunitinib (50 mg/day, 4 weeks on/2 weeks off; $N+S$ ) or pazopanib ( $800 \mathrm{mg} / \mathrm{day} ; \mathrm{N}+\mathrm{P}$ ) until progression/unacceptable toxicity. The nivolumab starting dose was $2 \mathrm{mg} /$ $\mathrm{kg}$ every 3 weeks, with planned escalation to $5 \mathrm{mg} / \mathrm{kg}$ every 3 weeks. Primary endpoints were safety and tolerability; antitumor activity was a secondary endpoint.

Results: Arm N + S enrolled 33 patients, 19 of whom were treatment-naive; this arm advanced to the expansion phase. Median follow-up was 50.0 months. Patients experienced high frequencies of adverse events (AEs) including treatment-related AEs (100\%), grade 3/4 treatment-related AEs (82\%), and treatment-related AEs leading to discontinuation (39\%). Investigator-assessed objective response rate (ORR) was 55\% (18/33) and median progression-free survival (PFS) was 12.7 months. Median overall survival (OS) was not reached. Arm N + P enrolled 20 patients, all had $\geq 1$ prior systemic therapy; this arm was closed due to dose-limiting toxicities and did not proceed to expansion. Median follow-up was 27.1 months. Patients treated with N + P experienced high frequencies of AEs including treatment-related AEs (100\%), grade 3/4 treatment-related AEs (70\%), and treatment-related AEs leading to discontinuation (25\%). Investigator-assessed ORR was 45\% (9/20) and median (Continued on next page)
\end{abstract}

\footnotetext{
*Correspondence: Asim.Amin@carolinashealthcare.org

Prior presentation: An earlier database lock from this study (with shorter follow-up) was presented at the European Society for Medical Oncology (ESMO) meeting, 2014. A partial presentation of the database lock included in this manuscript was made at the 16th International Kidney Cancer Symposium, 2017. Lingfeng Yang was an employee of Bristol-Myers Squibb at the time the study was performed.

'Immunotherapy program, Levine Cancer Institute, Carolinas HealthCare

System, 1024 Morehead Medical Drive, Charlotte, NC 28204, USA

Full list of author information is available at the end of the article
}

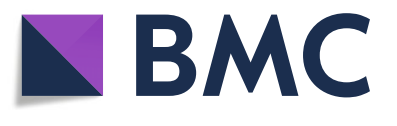

(c) The Author(s). 2018 Open Access This article is distributed under the terms of the Creative Commons Attribution 4.0 International License (http://creativecommons.org/licenses/by/4.0/), which permits unrestricted use, distribution, and reproduction in any medium, provided you give appropriate credit to the original author(s) and the source, provide a link to the Creative Commons license, and indicate if changes were made. The Creative Commons Public Domain Dedication waiver (http://creativecommons.org/publicdomain/zero/1.0/) applies to the data made available in this article, unless otherwise stated. 
(Continued from previous page)

PFS was 7.2 months. Median OS was 27.9 months.

Conclusions: The addition of standard doses of sunitinib or pazopanib to nivolumab resulted in a high incidence of high-grade toxicities limiting future development of either combination regimen. While there was no adverse impact on response and the OS outcome was notable, the findings suggest that the success of combination regimens based on immune checkpoint inhibitors and antiangiogenic drugs may be dependent on careful selection of the antiangiogenic component and dose.

Trial registration: Clinicaltrials.gov identifier: NCT01472081. Registered 16 November 2011.

Keywords: Metastatic renal cell carcinoma, Nivolumab, Immune checkpoint inhibitor, Sunitinib, Pazopanib, Antiangiogenic, Tyrosine kinase inhibitor

\section{Background}

Immunotherapeutic and antiangiogenic agents have improved treatment outcomes for patients with advanced or metastatic renal cell carcinoma (aRCC) [1-12]. Vascular endothelial growth factor (VEGF) receptor tyrosine kinase inhibitors (TKIs) are approved for first-and/or second-line aRCC treatment [3-5, 8-11]. Newer therapies targeting immune checkpoint pathways have also demonstrated significant clinical efficacy in aRCC, and are approved for this indication $[2,6,7,13]$.

The TKI sunitinib became a standard monotherapy option for treatment-naïve patients with aRCC after demonstrating superiority over interferon alpha; sunitinib has also demonstrated efficacy in pretreated patients [14]. In updated results from the key phase III trial comparing sunitinib with interferon alpha $(N=750)$, treatment-naïve patients with aRCC achieved an objective response rate $(\mathrm{ORR})$ of $47 \%$ versus $12 \%(P<0.001)$, a median progression-free survival (PFS) of 11 versus 5 months $(P<0.001)$, and a median overall survival (OS) of 26.4 versus 21.8 months $(P=0.051)$ [9]. In second-line trials of sunitinib in aRCC (post VEGF-targeted therapy), reported ORRs have ranged from 15 to $27 \%$, and median PFS has ranged from $\sim 5-18$ months [14]. The TKI pazopanib has also demonstrated efficacy in treating first- and second-line aRCC [15]. In a phase III study (VEG105192) of pazopanib versus placebo in treatment-naïve or pretreated patients $(N=435)$, median PFS was 9.2 versus 4.2 months $(P<0.0001)$, and ORR was $30 \%$ versus $3 \%$ $(P<0.001)$ [11]. The median OS was 22.9 versus 20.5 months (one-sided $P=0.224$ ), however, this analysis was confounded by the early, high rate of crossover of placebo patients to pazopanib [12]. In the open-label COMPARZ trial, which compared the efficacy and safety of pazopanib versus sunitinib as first-line therapy in 1110 patients with clear cell aRCC, PFS was 8.4 versus 9.5 months, respectively [8]. In an updated report, OS was found to be similar in both the pazopanib and sunitinib groups (28.3 vs 29.1 months) [16]. Sunitinib and pazopanib are considered to be similarly efficacious as first-line therapy in aRCC [17], and do not differentially impact outcomes with subsequent second-line treatment [18].

In a large expanded access program study $(N=4543)$, $95 \%$ of patients treated with sunitinib reported adverse events (AEs). The most commonly reported treatment-related grade 3 or 4 AEs included thrombocytopenia (10\%), fatigue (9\%), asthenia, handfoot syndrome, and neutropenia (each 7\%), hypertension (6\%), and diarrhea (5\%) [19]. In the VEG105192 trial, all patients in the pazopanib arm $(n=290)$ experienced $\geq 1 \mathrm{AE}$. The most common treatmentemergent grade 3 or 4 AEs with pazopanib were increased alanine aminotransferase (ALT; 12\%), increased aspartate aminotransferase (AST; 8\%), hyponatremia (5\%), lymphocytopenia (5\%), hypophosphatemia (4\%), hypertension (4\%), and diarrhea (4\%) [11].

Nivolumab, a fully human IgG4 programmed death-1 (PD-1) immune checkpoint inhibitor antibody, selectively blocks interaction between PD-1 expressed on activated T cells and the PD-1 ligands 1 and 2 expressed on tumor cells and other immune cells [20]. This blockade of PD-1-mediated signaling prevents T-cell inactivation and enhances antitumor immunity [20]. In the CheckMate 025 randomized phase III study $(N=821)$, median OS was longer with nivolumab compared with everolimus (25.0 vs 19.6 months; $P=0.002$ ) [7]. The ORR was also significantly higher in the nivolumab arm compared with everolimus (25\% vs $5 \%$; $P<$ 0.001). Median PFS was 4.6 months with nivolumab and 4.4 months with everolimus $(P=0.11)$. The most common treatment-related AEs in patients treated with nivolumab monotherapy were fatigue (33\%), nausea (14\%), and pruritus (14\%) [7]. On the basis of these results, nivolumab is approved in Europe and the United States for treatment of patients with aRCC who have received prior therapy $[7,21$, 22]. Nivolumab has further demonstrated clinical benefit in combination with ipilimumab (a monoclonal antibody that blocks cytotoxic T-lymphocyte-associated antigen-4 immune checkpoint signaling) in previously treated and treatment-naïve patients with aRCC, and this combination is now approved for the treatment of patients 
with intermediate- or poor-risk, treatment-naïve aRCC in the United States [21, 23, 24].

The antitumor activity of VEGF TKIs is attributed to their effect on angiogenesis, however, emerging data suggest that these agents may exert positive immunemodulatory activity in the suppressive tumor immune microenvironment. For example, sunitinib reduces the accumulation of myeloid-derived suppressor cells and reverses suppression of $\mathrm{T}$ cells in patients with aRCC $[25,26]$. The combination of immune checkpoint inhibitors plus TKI agents warrants further investigation. Other clinical trials have investigated the efficacy and safety of combination TKI and checkpoint inhibitorbased therapy in patients with aRCC $[27,28]$. Preliminary results from these studies have shown clinical benefit, however, some combinations have resulted in unacceptable toxicity [29].

Here, we report 3-year outcomes from the open-label, parallel-cohort, dose-escalation, phase I CheckMate 016 study of patients with aRCC treated with a combination of nivolumab and the TKIs sunitinib or pazopanib.

\section{Methods}

\section{Study design}

CheckMate 016 was a multicenter, open-label, phase I study. We report here the safety and efficacy outcomes of patients assigned to either nivolumab plus sunitinib $(\operatorname{arm} \mathrm{N}+\mathrm{S})$ or nivolumab plus pazopanib $(\operatorname{arm} \mathrm{N}+\mathrm{P})$. The safety and efficacy outcomes for CheckMate 016 patients assigned to different nivolumab plus ipilimumab treatment regimens have been reported previously [23]. Patients were assigned to treatment arms $\mathrm{N}+\mathrm{S}$ and $\mathrm{N}+$ $\mathrm{P}$ in two phases: an escalation phase to determine the maximum tolerated dose (MTD) to gain safety and tolerability information, and a planned expansion phase to gain additional safety information.

\section{Dosing}

The starting dose of nivolumab was $2 \mathrm{mg} / \mathrm{kg}$ of body weight intravenously every 3 weeks (N2; dose-escalation phase), with planned increase to $5 \mathrm{mg} / \mathrm{kg}$ intravenously every 3 weeks (N5; dose-expansion phase). Each treatment cycle was 6 weeks in duration; patients received nivolumab on days 1 and 22 in combination with sunitinib $(50 \mathrm{mg}$ orally on days $1-28$ of each 6 -week cycle; arm $\mathrm{N}+\mathrm{S}$ ) or pazopanib (800 mg orally on each day of the 6 -week cycle; $\operatorname{arm} \mathrm{N}+\mathrm{P}$ ) until disease progression/unacceptable toxicity. Expansion phase recruitment was dependent on the MTD assessed by the modified toxicity probability interval [30] during dose escalation. If the MTD of nivolumab was $\geq 5 \mathrm{mg} / \mathrm{kg}$ in either arm, the arm was further expanded to include treatment-naïve patients. Patients could discontinue treatment due to investigator-assessed, Response Evaluation Criteria in Solid Tumors (RECIST) v1.1-defined disease progression, unacceptable toxicity, withdrawal of consent, or per the investigator's clinical judgment. If the combined incidence of treatment-related toxicity required discontinuation of $>30 \%$ of treated patients, further enrollment to that arm was paused and a decision on whether to continue dosing was made based on the observed aggregate (acute and chronic) toxicities.

Sunitinib and pazopanib dose delays, reductions, and escalations were permitted per the approved product labels. All dose reductions of sunitinib were in 12.5-mg increments and were relative to the lowest dose level of the current cycle. The initial intra-patient dose reduction of pazopanib was to $400 \mathrm{mg}$. Additional pazopanib dose reductions were in $200-\mathrm{mg}$ increments and were relative to the lowest dose level of the current cycle. If the current dose level was $25 \mathrm{mg}$ (sunitinib) or $200 \mathrm{mg}$ (pazopanib) and the toxicity guidelines required a further permanent dose reduction to mitigate sunitinib or pazopanib-related toxicity, the patient was discontinued from receiving that study drug. The pazopanib or sunitinib dosing period could not be extended to compensate for interruptions in study treatment. Nivolumab intra-patient dose reductions or escalations were not permitted, however, administration could be delayed based on specific AE criteria. Patients could resume treatment with nivolumab, pazopanib, or sunitinib when treatment-related $\mathrm{AE}(\mathrm{s})$ resolved to grade 1 or baseline. If a treatment-related $\mathrm{AE}$ occurred after cycle 1 and met criteria for discontinuation but was attributable to the TKI and not to nivolumab, or if a patient stopped the TKI secondary to chronic toxicity, continuation on nivolumab monotherapy was permitted.

\section{Patients}

Patients eligible for inclusion were $\geq 18$ years of age with histologically confirmed aRCC with a clear cell component (escalation and expansion phases) or non-clear cell RCC, limited to papillary, chromophobe or unclassified histology (escalation phase only), had measurable disease per RECIST v1.1 criteria, Karnofsky performance status $\geq 80 \%$, and were categorized with favorable- or intermediate-risk Memorial Sloan Kettering Cancer Center prognostic score at study enrollment. Patients were required to have received $\geq 1$ prior systemic treatment regimen in the advanced/metastatic setting to be eligible for the escalation phase. Patients eligible for the treatment-naïve expansion phase were not permitted to have received any prior systemic therapy in the advanced/metastatic setting. Patients who received prior pazopanib were assigned to $\operatorname{arm~} \mathrm{N}+\mathrm{S}$, while those who received prior sunitinib were assigned to $\operatorname{arm} \mathrm{N}+\mathrm{P}$. Patients with prior treatment other than sunitinib or pazopanib could be assigned to either arm. Patients who received prior sunitinib or pazopanib and previously required permanent discontinuation due to toxicity, or required dose reduction/delay during the first 12 weeks of 
therapy due to toxicity were excluded, as were patients who had received both prior sunitinib and pazopanib. Patients with active central nervous system metastases, poorly controlled hypertension, evidence of active bleeding or bleeding susceptibility within 30 days of enrollment, or impairment of gastrointestinal function or gastrointestinal disease that may have significantly altered the absorption of either antiangiogenic TKI were excluded. Patients with current or recent history of a known or suspected autoimmune disorder requiring systemic corticosteroids equivalent to $\geq 10 \mathrm{mg}$ of oral prednisone were also excluded.

\section{Study endpoints and assessments}

The primary objective was to assess overall safety and tolerability of nivolumab plus sunitinib or pazopanib in order to determine the MTD of these combination regimens. Safety and tolerability were defined by incidence of AEs occurring $\leq 100$ days after the last study treatment dose, and the worst toxicity grade of clinical laboratory tests, including hematology, comprehensive metabolic profile, and urinalysis. AEs were graded according to National Cancer Institute Common Terminology Criteria for Adverse Events v4.0. Additional safety assessments included determination of treatment-related AEs leading to discontinuation and any-grade select treatment-related AEs, defined as those with possible immune-mediated etiology.

Secondary endpoints included ORR, duration of response (DoR), and PFS, all investigator-assessed per RECIST v1.1. ORR was defined as the proportion of all treated patients whose best overall response was a complete or a partial response. DoR was calculated for all treated patients who achieved a complete or partial response, with DoR defined as the time between dates of first response and of disease progression or death, whichever occurred first. PFS was defined as the time from dates of first study medication dose to first disease progression or death. OS, an exploratory endpoint, was defined as the time from date of first dose of study medication to the date of death (any reason). If the patient did not die, OS was censored on the last date the subject was known to be alive. PFS and OS rates were calculated over time. Tumor assessments were done at screening, every 6 weeks ( \pm 1 week) from the first study treatment dose for the first four patient visits, and every 12 weeks ( \pm 1 week) thereafter until disease progression.

\section{Statistical analysis}

The study sample size required to determine MTD in this phase I dose-escalation trial for each dose was dependent on observed toxicity and posterior inference. Six eligible patients per arm were to be treated with the $\mathrm{N} 2$ dosing regimen initially. Additional patients could be assigned to either the same or the higher nivolumab dose level cohort based on the number of dose-limiting toxicities (DLTs) observed. Depending on the number observed, de-escalation could occur without the possibility of re-escalation. If deemed safe, additional patients were to be treated at the N5 level in combination with sunitinib or pazopanib to gain additional safety information. Administration of N5 to 26 or 32 patients was determined adequate to provide $90 \%$ probability of observing $\geq 1$ occurrence of any AE that would occur with an $8 \%$ or $7 \%$ incidence in the population from which the study sample was selected for the $\mathrm{N}+\mathrm{S}$ or $\mathrm{N}+\mathrm{P}$ arms, respectively. At the end of the trial, the MTD was estimated as the dose with the smallest difference of estimated and target toxicity across all doses.

Safety and efficacy analyses included all patients who received $\geq 1$ dose of study medication in either arm. AEs were summarized and reported by organ system, preferred term, treatment arm, and dose cohort, coded per MedDRA. ORR and its 95\% exact confidence interval $(\mathrm{CI})$ were determined by Clopper and Pearson methodology, while the Kaplan-Meier method was used to analyze DoR and its 95\% CI. PFS and OS were plotted using the Kaplan-Meier method, with median and corresponding two-sided 95\% CIs reported. PFS and OS rate point estimates were derived from Kaplan-Meier analyses. Statistical analyses comparing safety between arms were not performed.

\section{Results}

\section{Patient population and baseline characteristics}

A total of 194 patients were enrolled in the study from February 2012 to May 2014; 153 were treated, with 33 assigned to arm $\mathrm{N}+\mathrm{S}$ and 20 assigned to arm $\mathrm{N}+\mathrm{P}$ (Additional file 1: Table S1). The remainder received nivolumab plus ipilimumab as previously reported [23]. In arm $\mathrm{N}+\mathrm{S}$, seven patients completed the dose-escalation phase at the N2 dose, with a further 26 patients included in the dose-expansion phase at the N5 dose $(N=33)$. In $\operatorname{arm~N}+\mathrm{S}, 18$ (55\%) patients had one or more dose reductions of sunitinib and $21(64 \%)$ patients had at least one nivolumab dose delay. In arm N + P, seven (35\%) patients had one or more dose reductions of pazopanib and 11 (55\%) patients had at least one nivolumab dose delay. Arm $\mathrm{N}+\mathrm{P}$ was not expanded beyond the $\mathrm{N} 2$ dose as per prespecified criteria for DLTs; three patients had elevated ALT/AST and one had fatigue. Fourteen (42.4\%) patients in arm $\mathrm{N}+\mathrm{S}$ had received $\geq 1$ prior systemic therapy, and 19 (57.6\%) patients (all enrolled in the $\mathrm{N}+\mathrm{S}$ expansion arm) were treatment-naïve. All 20 patients in arm $\mathrm{N}+\mathrm{P}$ had received $\geq 1$ prior systemic therapy.

Baseline demographic and clinical characteristics are detailed in Table 1. At data cutoff (June 12, 2017), 
Table 1 Baseline demographic and clinical characteristics of treated patients

\begin{tabular}{|c|c|c|}
\hline Characteristic & $N+S(N=33)$ & $N+P(N=20)$ \\
\hline \multicolumn{3}{|l|}{ Age, years } \\
\hline Median (range) & $57.0(38-75)$ & $56.0(40-72)$ \\
\hline Age < 65 years, $n(\%)$ & $24(72.7)$ & $17(85.0)$ \\
\hline \multicolumn{3}{|l|}{ Sex, $n(\%)$} \\
\hline Male & $26(78.8)$ & $18(90.0)$ \\
\hline Female & $7(21.2)$ & $2(10.0)$ \\
\hline \multicolumn{3}{|l|}{ Race, $n(\%)$} \\
\hline Caucasian & $28(84.8)$ & $18(90.0)$ \\
\hline Asian & $1(3.0)$ & 0 \\
\hline Black/African American & $2(6.1)$ & $1(5.0)$ \\
\hline Other & $2(6.1)$ & $1(5.0)$ \\
\hline \multicolumn{3}{|l|}{ Ethnicity, n (\%) } \\
\hline Hispanic/Latino & $2(6.1)$ & 0 \\
\hline Not Hispanic/Latino & $29(87.9)$ & $18(90.0)$ \\
\hline Not reported & $2(6.1)$ & $2(10.0)$ \\
\hline \multicolumn{3}{|l|}{ MSKCC risk category, $n$ (\%) } \\
\hline Favorable & $16(48.5)$ & $4(20.0)$ \\
\hline Intermediate & $16(48.5)$ & $14(70.0)$ \\
\hline Poor & $1(3.0)$ & $2(10.0)$ \\
\hline Prior surgery, $n$ (\%) & $33(100.0)$ & $20(100.0)$ \\
\hline Prior radiotherapy, n (\%) & $5(15.2)$ & $10(50.0)$ \\
\hline Prior systemic therapy, $n$ (\%) & $14(42.4)$ & $20(100.0)$ \\
\hline VEGFR inhibitor & $5(15.2)$ & $17(85.0)$ \\
\hline Other antiangiogenic & $7(21.2)$ & $17(85.0)$ \\
\hline Cytokine & $9(27.3)$ & $10(50.0)$ \\
\hline mTOR inhibitor & 0 & $3(15.0)$ \\
\hline Other & $3(9.1)$ & $4(20.0)$ \\
\hline \multicolumn{3}{|l|}{ No. of prior therapies, $n$ (\%) } \\
\hline 0 & $19(57.6)$ & 0 \\
\hline 1 & $14(42.4)$ & $14(70.0)$ \\
\hline 2 & 0 & $4(20.0)$ \\
\hline 3 & 0 & $1(5.0)$ \\
\hline$\geq 4$ & 0 & $1(5.0)$ \\
\hline \multicolumn{3}{|l|}{ Treatment setting, ${ }^{a} n(\%)$} \\
\hline Adjuvant & $3(9.1)$ & $4(20.0)$ \\
\hline Metastatic & 0 & $2(10.0)$ \\
\hline Neoadjuvant & $11(33.3)$ & $16(80.0)$ \\
\hline
\end{tabular}

${ }^{a}$ More than one setting per patient may be reflected in the frequency

median follow-up was $50.0(\mathrm{~N}+\mathrm{S})$ and $27.1(\mathrm{~N}+\mathrm{P})$ months. Median duration of therapy was 45.1 weeks for nivolumab and 28 weeks for sunitinib $(\mathrm{N}+\mathrm{S})$; median duration of therapy was 15.1 weeks for nivolumab and 13.9 weeks for pazopanib $(\mathrm{N}+\mathrm{P})$.

\section{Safety and tolerability}

Among all patients assigned to either arms $\mathrm{N}+\mathrm{S}$ or $\mathrm{N}+$ $\mathrm{P}, 100 \%$ experienced a treatment-related $\mathrm{AE}$ of any grade, and $81.8 \%$ and $70.0 \%$ experienced a grade 3 or 4 treatment-related $\mathrm{AE}$, respectively (Table 2 ). There were no grade 5 treatment-related AEs in either study arm. Select treatment-related AEs (those with possible immune-mediated etiology) included skin, endocrine, gastrointestinal, hepatic, renal, and pulmonary events (Table 2).

For patients in arm $\mathrm{N}+\mathrm{S}$, the most common any-grade treatment-related AEs were fatigue (84.8\%). diarrhea (63.6\%), dysgeusia (63.6\%), and nausea (57.6\%). The most common grade 3 or 4 treatment-related AEs were hypertension (18.2\%), increased ALT (18.2\%), increased AST (9.1\%), diarrhea (9.1\%), and fatigue (9.1\%). Treatmentrelated AEs of any grade leading to discontinuation occurred in 13 (39.4\%) patients in this arm (Table 2), and $13(39.4 \%)$ patients received a systemic corticosteroid to manage AEs (Additional file 2: Figure S1).

For patients in arm $\mathrm{N}+\mathrm{P}$, the most common any-grade treatment-related AEs were also fatigue $(60.0 \%)$, diarrhea $(60.0 \%)$, dysgeusia $(50.0 \%)$, and nausea (75.0\%). Similarly, the most common grade 3 or 4 treatment-related AEs were hypertension (10.0\%), increased ALT (20.0\%), increased AST (20.0\%), diarrhea (20.0\%), and fatigue (15.0\%). Treatment-related AEs of any grade leading to discontinuation occurred in five $(25.0 \%)$ patients in this arm (Table 2), and $12(60.0 \%)$ patients received a systemic corticosteroid to manage AEs (Additional file 2: Figure S1).

\section{Efficacy}

In treatment arm $\mathrm{N}+\mathrm{S}$, the confirmed ORR $(95 \% \mathrm{CI})$ was $54.5 \%$ (36.4-71.9). Two (6.1\%) patients achieved a complete response, 16 (48.5\%) achieved a partial response, $11(33.3 \%)$ had stable disease, one $(0.3 \%)$ had progressive disease, and in three patients $(9.1 \%)$, response was undeterminable. Responses were sustained with a median $(95 \%$ CI) DoR of 60.2 (37.1-not reached [NR]) weeks. Four of the 18 responders $(22.2 \%)$ in this arm have an ongoing response as of the data cutoff (Fig. 1); notably, eight of the 18 responders $(44.4 \%)$ had a response that was sustained for $\geq 6$ months after discontinuation of therapy, with one responder maintaining a response for more than 4 years after discontinuing $\mathrm{N}+\mathrm{S}$ therapy. Most patients with a baseline and $\geq 1$ post-baseline assessment experienced a reduction in target lesion size; 20 of 30 evaluable patients in this arm experienced a reduction of $\geq 30 \%$ (Additional file 3: Figure S2). Median (95\% CI) PFS was 12.7 (11.016.7) months (Fig. 2a). PFS rates at 6, 12, 18, and 24 months were $79.4 \%, 51.8 \%, 29.6 \%$, and $29.6 \%$. At a median follow-up of 50.0 months, the median OS was NR (36.8-NR) (Fig. 2b). OS rates at 12, 18, and 24 months 
Table 2 TRAEs (in $\geq 30 \%$ of patients), select TRAEs, and TRAEs leading to discontinuation in $\geq 2$ patients

\begin{tabular}{|c|c|c|c|c|}
\hline \multirow[t]{3}{*}{ TRAE, preferred term, $n(\%)^{\mathrm{a}}$} & \multicolumn{4}{|c|}{ Treatment arm } \\
\hline & \multicolumn{2}{|c|}{$N+S(N=33)$} & \multicolumn{2}{|c|}{$N+P(N=20)$} \\
\hline & All grades & Grade 3 or 4 & All grades & Grade 3 or 4 \\
\hline Total patients with an event & $33(100.0)$ & $27(81.8)$ & $20(100.0)$ & $14(70.0)$ \\
\hline Fatigue & $28(84.8)$ & $3(9.1)$ & $12(60.0)$ & $3(15.0)$ \\
\hline Diarrhea & $21(63.6)$ & $3(9.1)$ & $12(60.0)$ & $4(20.0)$ \\
\hline Dysgeusia & $21(63.6)$ & 0 & $10(50.0)$ & 0 \\
\hline Nausea & $19(57.6)$ & $1(3.0)$ & $15(75.0)$ & 0 \\
\hline Hypertension & $16(48.5)$ & $6(18.2)$ & $5(25.0)$ & $2(10.0)$ \\
\hline Decreased appetite & $16(48.5)$ & $1(3.0)$ & $8(40.0)$ & 0 \\
\hline Increased ALT & $13(39.4)$ & $6(18.2)$ & $5(25.0)$ & $4(20.0)$ \\
\hline Palmar-plantar erythrodysesthesia syndrome & $13(39.4)$ & 0 & 0 & 0 \\
\hline Increased AST & $12(36.4)$ & $3(9.1)$ & $6(30.0)$ & $4(20.0)$ \\
\hline Blood creatinine increased & $11(33.3)$ & $2(6.1)$ & $1(5.0)$ & 0 \\
\hline Hypothyroidism & $11(33.3)$ & 0 & $4(20.0)$ & $1(5.0)$ \\
\hline Dyspepsia & $11(33.3)$ & 0 & $4(20.0)$ & 0 \\
\hline Dry skin & $11(33.3)$ & 0 & $2(10.0)$ & 0 \\
\hline Mucosal inflammation & $10(30.3)$ & 0 & $5(25.0)$ & 0 \\
\hline Dry mouth & $10(30.3)$ & 0 & $1(5.0)$ & 0 \\
\hline Arthralgia & $8(24.2)$ & 0 & $7(35.0)$ & $1(5.0)$ \\
\hline Pruritus & $8(24.2)$ & 0 & $7(35.0)$ & 0 \\
\hline Vomiting & $7(21.2)$ & $1(3.0)$ & $6(30.0)$ & 0 \\
\hline \multicolumn{5}{|l|}{ Select TRAE, organ class, $n(\%)^{\mathrm{b}}$} \\
\hline Skin & $26(78.8)$ & $2(6.1)$ & $11(55.0)$ & 0 \\
\hline Endocrine & $12(36.4)$ & 0 & $5(25.0)$ & $2(10.0)$ \\
\hline Gastrointestinal & $21(63.6)$ & $3(9.1)$ & $12(60.0)$ & $4(20.0)$ \\
\hline Hepatic & $15(45.5)$ & $8(24.2)$ & $7(35.0)$ & $4(20.0)$ \\
\hline Renal & $13(39.4)$ & $4(12.1)$ & $1(5.0)$ & 0 \\
\hline Pulmonary & $1(3.0)$ & $1(3.0)$ & $1(5.0)$ & 0 \\
\hline \multicolumn{5}{|c|}{ TRAE leading to discontinuation, preferred term, $n(\%)^{a}$} \\
\hline Total patients with an event & $13(39.4)$ & $11(33.3)$ & $5(25.0)$ & $4(20.0)$ \\
\hline Increased ALT & $3(9.1)$ & $2(6.1)$ & $3(15.0)$ & $3(15.0)$ \\
\hline Acute kidney injury & $3(9.1)$ & $1(3.0)$ & 0 & 0 \\
\hline Increased AST & $1(3.0)$ & $1(3.0)$ & $3(15.0)$ & $3(15.0)$ \\
\hline
\end{tabular}

Includes events reported between the first dose and 100 days after the last dose of study therapy

${ }^{b}$ Includes events reported between the first dose and 30 days after the last dose of study therapy

were $90.9 \%, 81.5 \%$, and $81.5 \%$. Among treated patients, $45.5 \%$ in this arm received subsequent medical intervention, with $42.4 \%$ receiving systemic therapy.

In treatment arm $\mathrm{N}+\mathrm{P}$, the confirmed ORR $(95 \% \mathrm{CI})$ was $45.0 \%$ (23.1-68.5). There were no complete responses, nine (45.0\%) patients had partial responses, seven $(35.0 \%)$ had stable disease, and four (20.0\%) had progressive disease. Responses were sustained with a median $(95 \% \mathrm{CI})$ DoR of 30.1 (12.1-174.1) weeks (Fig. 3). Ten of 19 evaluable patients treated with $\mathrm{N}+\mathrm{P}$ experienced a reduction in target lesion size of $\geq 30 \%$ (Additional file 4: Figure S3). Median (95\% CI)
PFS was $7.2(2.8-11.1)$ months (Fig. 4a). The 6-month PFS rate was $54.9 \%$, and not calculated for the subsequent months in this arm. At a median follow-up of 27.1 months, median OS (95\% CI) was 27.9 months (13.3-47.0) (Fig. 4b). OS rates at 12,18 , and 24 months were $84.4 \%, 73.9 \%$, and 63.3\%. Among treated patients, $80.0 \%$ received subsequent medical intervention, with $70.0 \%$ receiving systemic therapy.

\section{Discussion}

In this first study to combine nivolumab with antiangiogenic TKIs, notable clinical activity was observed 

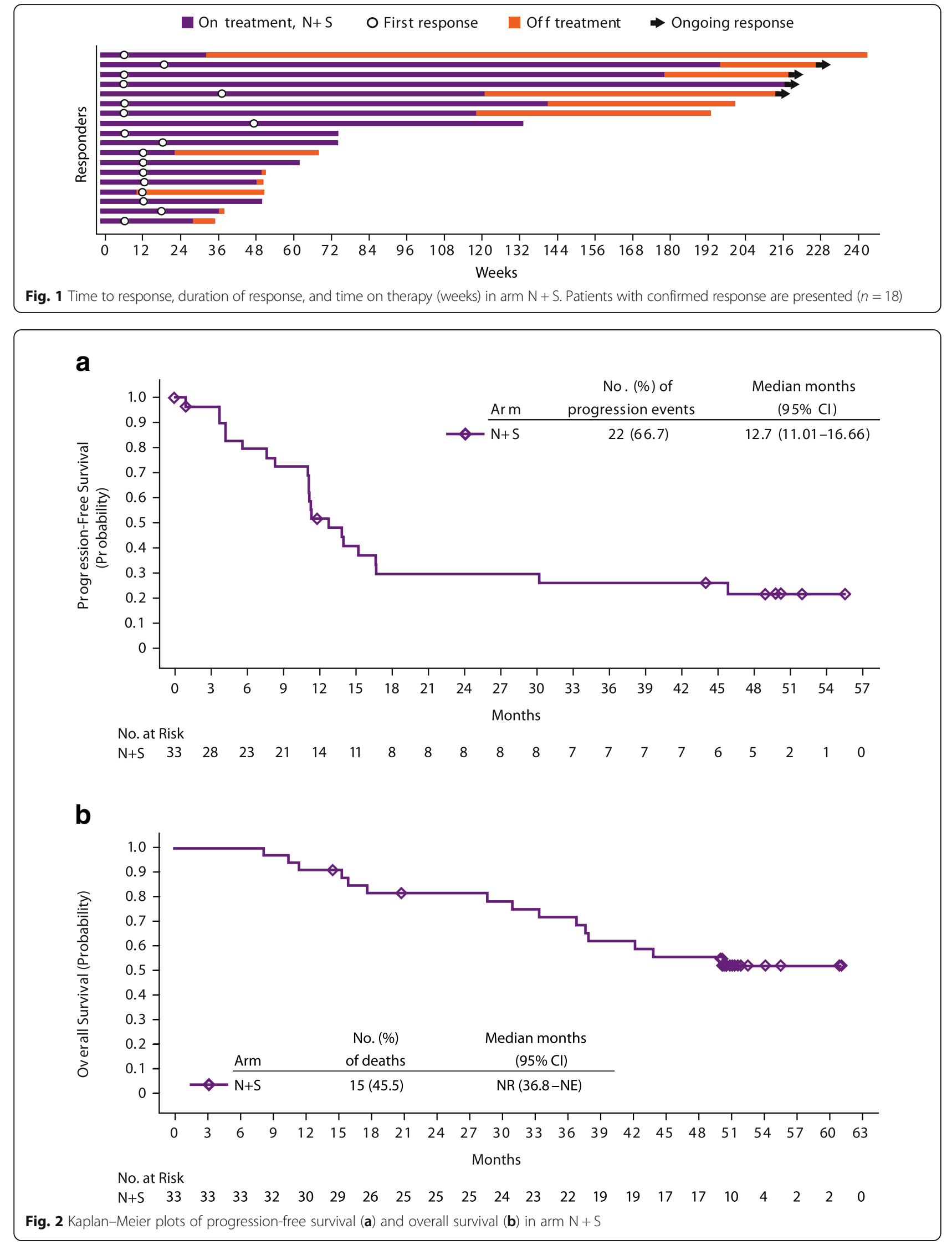


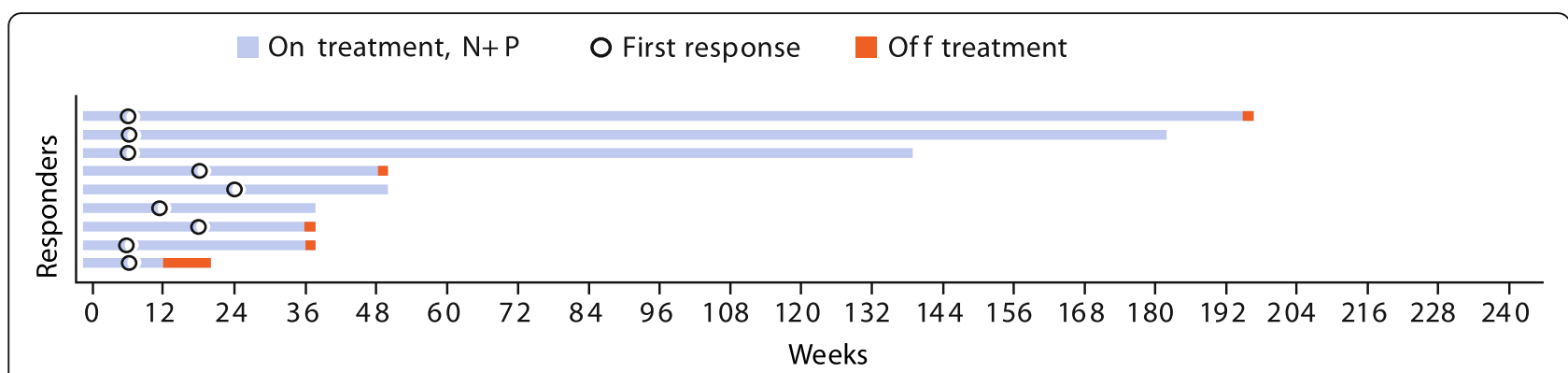

Fig. 3 Time to response, duration of response, and time on therapy (weeks) in arm N + P. Patients with confirmed response are presented ( $n=9$, no ongoing responses were observed)

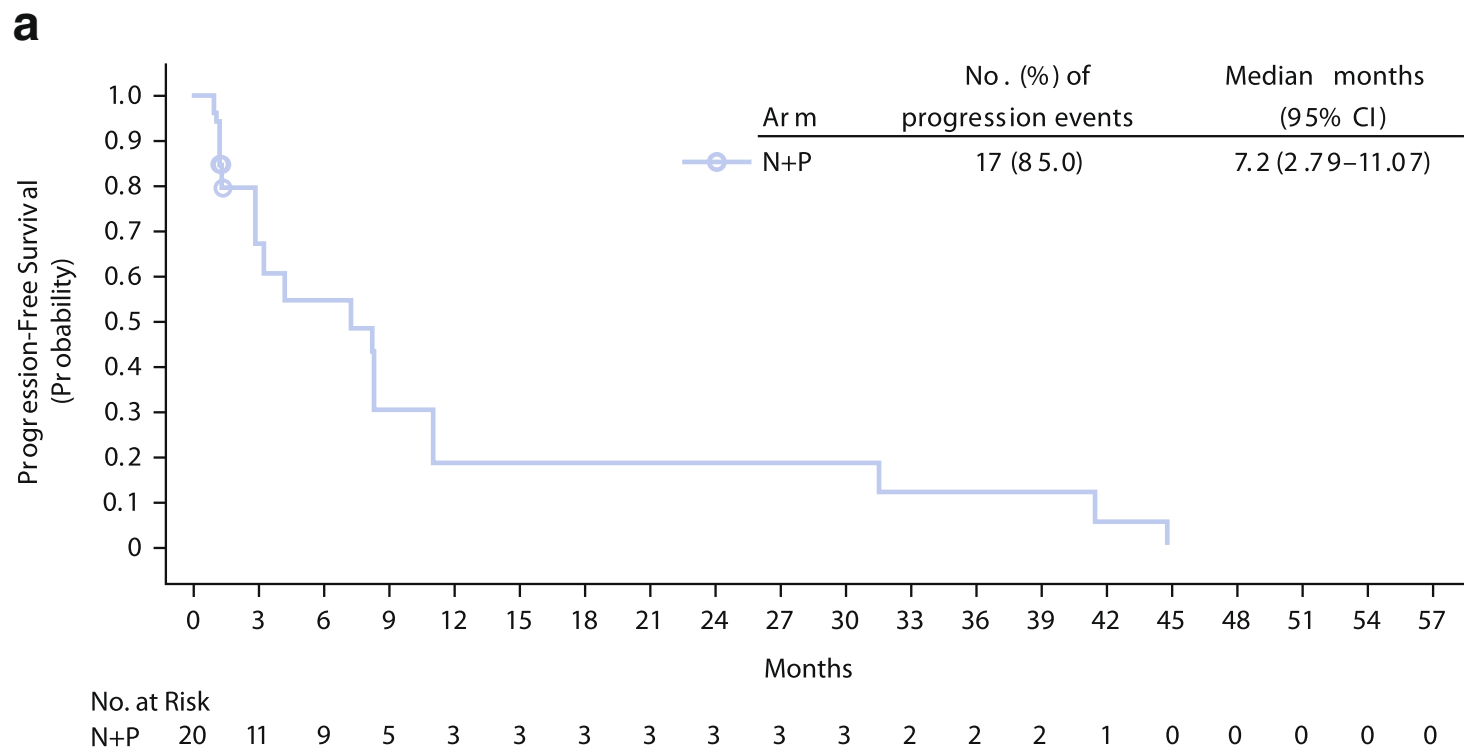

b

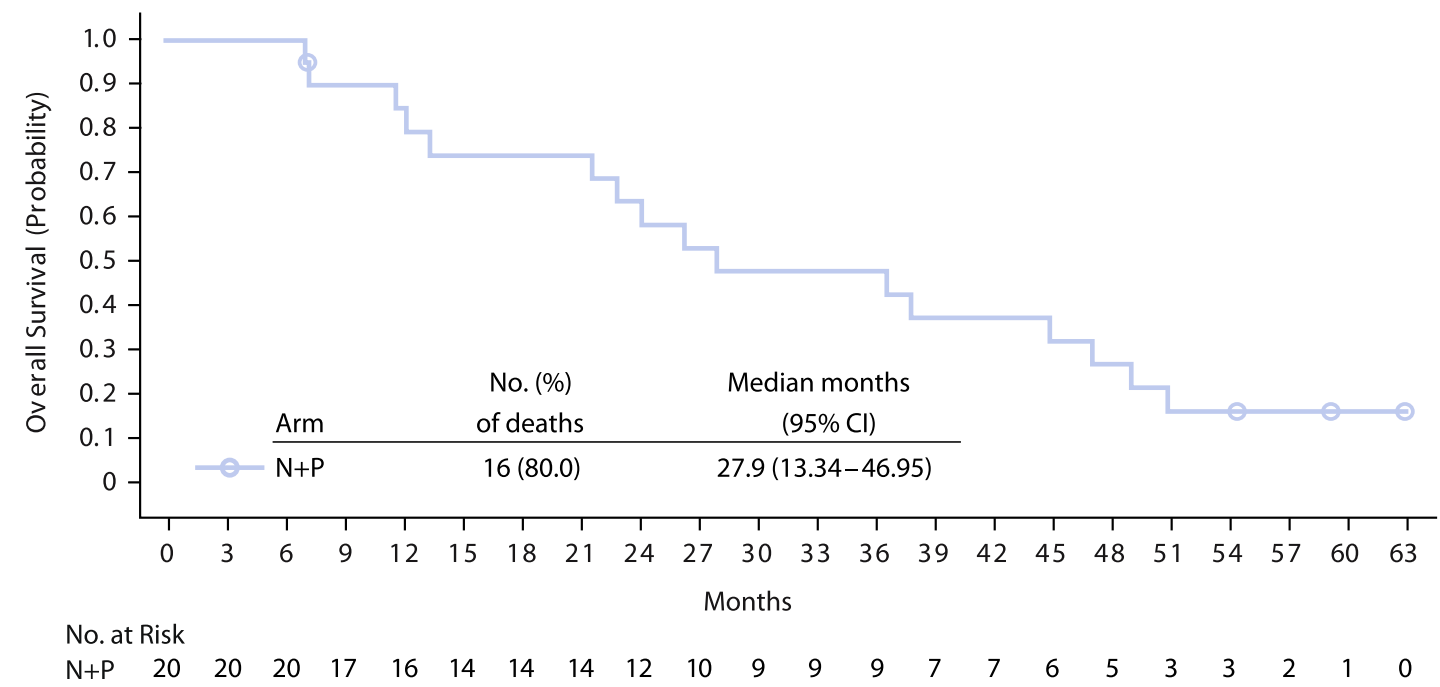

Fig. 4 Kaplan-Meier plots of progression-free survival (a) and overall survival (b) in arm N + P 
in patients with aRCC, albeit with substantial toxicity. Extended follow-up of the CheckMate 016 study in aRCC did not reveal any late-emergent select AEs with the nivolumab plus TKI combinations [31]. However, both $\mathrm{N}+\mathrm{S}$ and $\mathrm{N}+\mathrm{P}$ combinations resulted in greater frequencies of high-grade/treatment-related AEs and AEs leading to discontinuation than previously observed with nivolumab, sunitinib, or pazopanib monotherapy.

Based on the safety results in the N2 dose-escalation phase, arm $\mathrm{N}+\mathrm{S}$ advanced to expansion at the N5 dose level, while arm $\mathrm{N}+\mathrm{P}$ was closed due to early DLTs observed in the initial escalation phase. Overall, $81.8 \%$ and $70.0 \%$ of patients in arms $\mathrm{N}+\mathrm{S}$ and $\mathrm{N}+\mathrm{P}$, respectively, experienced a treatment-related grade 3 or $4 \mathrm{AE}$. In comparison, a similar proportion of patients previously experienced grade 3 or 4 treatment-related AEs with sunitinib $(69 \%$ of patients treated for $0-4$ years, data pooled from 807 patients across multiple trials) [32]. However, this rate was higher than the rate of all-cause grade 3 or 4 AEs previously reported with pazopanib monotherapy (33\% or $7 \%$ of patients, respectively, in a phase III study [N=435]) [11], and higher than the rate of grade 3 or 4 treatment-related AEs previously reported with nivolumab monotherapy (19\% of patients in a phase III study [ $N=410]$ ) [7]. Any-grade and grade 3 or 4 treatment-related select AEs also occurred more frequently in patients treated with $\mathrm{N}+\mathrm{S}$ and $\mathrm{N}+\mathrm{P}$ versus those treated in the nivolumab $3 \mathrm{mg} / \mathrm{kg}$ plus ipilimumab $1 \mathrm{mg} / \mathrm{kg}(N=47)$ arm of the CheckMate 016 trial reported earlier [23].

Treatment-related AEs of any grade leading to discontinuation occurred in $39.4 \%$ and $25.0 \%$ of patients in arms $\mathrm{N}+\mathrm{S}$ and $\mathrm{N}+\mathrm{P}$. In comparison, previous trials have reported that $11 \%$ of patients with cytokine-refractory aRCC discontinued sunitinib treatment due to all-cause AEs [10]; 19\% (pretreated) and $12 \%$ (treatment-naïve) of patients discontinued pazopanib treatment due to all-cause AEs [11]; and $8 \%$ of patients with aRCC who received second-line nivolumab monotherapy discontinued due to a treatment-related $\mathrm{AE}$ [7]. In the phase III trial of first-line nivolumab plus ipilimumab versus sunitinib, $22 \%$ of patients in the nivolumab plus ipilimumab combination arm and $12 \%$ in the sunitinib arm reported treatment-related AEs leading to discontinuation [24]. An important outcome of the current study, and one that was observed in the nivolumab plus ipilimumab arm of CheckMate 016 [23], as well as with other immune checkpoint inhibitor-based regimens in various tumor types [33-36], is that responses were noted to continue beyond treatment discontinuation.

While associated with substantial toxicity, the addition of sunitinib or pazopanib to nivolumab showed sustained antitumor activity in this small, favorable or intermediate risk, mixed population of treatment-naïve and pretreated aRCC patients, with more durable responses compared with monotherapy. Confirmed ORRs of $54.5 \%$ and $45.0 \%$ were reported in arms $\mathrm{N}+\mathrm{S}$ and $\mathrm{N}+\mathrm{P}$, respectively, with median DoRs of 60.2 and 30.1 weeks. High ORRs have also been reported with other immune checkpoint inhibitor plus antiangiogenic combinations in early-phase studies of aRCC. These include pembrolizumab in combination with axitinib (ORR 73\% in 52 treatment-naïve patients) [27] or lenvatinib (ORR 63.3\% in 30 treatment-naïve and pretreated patients) [28]; avelumab in combination with axitinib (ORR 58\% in 55 treatment-naïve RCC patients) [37]; and atezolizumab in combination with bevacizumab (ORRs of 32\% in 101 treatment-naïve RCC patients [phase II] [38] and $37 \%$ in 454 treatment-naïve RCC patients [phase III]) [39]. Safety results from the aforementioned combination studies were reported as acceptable and in most cases comparable to previous reports of either agent as monotherapy [27, 28, 37-39]. A previous phase I/II study assessing the safety and efficacy of pembrolizumab in combination with pazopanib in patients with aRCC demonstrated preliminary efficacy albeit with significant hepatotoxicity [29], suggesting that the choice of TKI may impact the overall risk versus benefit outcome of the various combination therapies under investigation.

In the current study, which at present has the longest follow-up for a combination regimen based on an immune checkpoint inhibitor and a TKI, favorable antitumor activity and survival benefits were observed in arm $\mathrm{N}+\mathrm{S}$. Two (6.1\%) patients had a complete response and 16 (48.5\%) achieved partial response. Most responses occurred shortly after treatment initiation, and were of notable magnitude in both arms. Of all patients in arm $\mathrm{N}+\mathrm{S}$ who had a baseline target lesion and at least one post-baseline assessment, zero patients had increases in target lesion tumor burden, and $67 \%$ of patients had a reduction of $\geq 30 \%$ in their target lesion tumor burden at a median follow-up of $>4$ years. Median OS was NR at the time of this analysis in arm $\mathrm{N}+\mathrm{S}$, and was 27.9 months in arm $\mathrm{N}$ $+\mathrm{P}$. The longer median duration of nivolumab treatment in arm $\mathrm{N}+\mathrm{S}$ (45.1 weeks) versus arm $\mathrm{N}+\mathrm{P}$ (15.1 weeks) may be attributable to inclusion of treatment-naïve patients and a longer duration of benefit in this arm.

\section{Conclusions}

While the duration and depth of response observed in arm $\mathrm{N}+\mathrm{S}$ was notable, the toxicity observed in this study with the currently approved standard dose of sunitinib or pazopanib in combination with nivolumab precludes further clinical evaluation of either combination. The tolerability results observed in the current study, particularly in arm $\mathrm{N}$ $+\mathrm{P}$, may reflect toxicity due to the choice and standard dose of the TKI rather than nivolumab toxicity. Indeed, as mentioned previously, the combination of pembrolizumab and pazopanib (at the same dose as used in this study) was associated with significant hepatotoxicity [29], but regimens 
comprising pembrolizumab and axitinib or lenvatinib appear to be associated with more manageable safety profiles $[27,28]$. This suggests that the respective efficacy and safety of combination regimens based on immune checkpoint inhibitors and antiangiogenic drugs may depend on selection of the antiangiogenic component. Nevertheless, confidence in the concept of combined immune checkpoint blockade and antiangiogenesis is demonstrated by the number of ongoing phase III studies evaluating the combination of an immune checkpoint inhibitor with an anti-VEGF TKI [3943]. These ongoing studies will help further define the role of these combinations in the evolving armamentarium for treating aRCC.

\section{Limitations}

This small phase I study sought to determine a safe and tolerable dose of nivolumab as part of a combination regimen with standard doses of the TKIs sunitinib or pazopanib, to enable further evaluation of the safety and efficacy of such combinations in patients with aRCC. This study was only powered to assess overall safety and tolerability in order to determine the MTD and recommended phase II dose of each combination regimen in this setting. The antitumor activity of nivolumab plus TKI combinations was assessed as a secondary endpoint in this study by the investigatorassessed RECIST v1.1 criteria. Additionally, due to the DLTs observed preventing the expansion of arm $\mathrm{N}+\mathrm{P}$, this arm contained only pretreated patients, while the $\mathrm{N}+\mathrm{S}$ arm contained a mixed population of pretreated patients (nivolumab $2 \mathrm{mg} / \mathrm{kg}$ plus sunitinib $50 \mathrm{mg}$ ) and treatment-naïve patients (nivolumab $5 \mathrm{mg} / \mathrm{kg}$ plus sunitinib $50 \mathrm{mg}$ ). No direct comparisons can therefore be made regarding relative efficacy or safety between nivolumab plus sunitinib or nivolumab plus pazopanib combination regimens, or between either combination therapy and any monotherapy. Ongoing studies will help determine if different dosing regimens, or different immuno-oncology plus TKI combinations, could yield safe and efficacious outcomes for patients with aRCC.

\section{Additional files}

Additional file 1: Table S1. Concomitant systemic corticosteroids for adverse event management. (DOCX $46 \mathrm{~kb}$ )

Additional file 2: Figure S1. Patient disposition. (DOCX $512 \mathrm{~kb}$ )

Additional file 3: Figure S2. Best percent change from baseline in target lesion tumor burden up to Response Evaluation Criteria in Solid Tumors version 1.1 (RECIST v1.1) progression. Dashed lines denote 30\% decrease and 20\% increase in tumor burden. Patients whose target lesion resolved 100\% may have had concurrent progression of nontarget lesions. Patients with baseline target lesion and at least one post-baseline assessment of target lesion are presented ( $N+S, n=30)$. (DOCX $229 \mathrm{~kb}$ )

Additional file 4: Figure $\mathbf{S 3}$. Best percent change from baseline in target lesion tumor burden up to Response Evaluation Criteria in Solid Tumors version 1.1 (RECIST v1.1) progression. Dashed lines denote 30\% decrease and 20\% increase in tumor burden. Patients whose target lesion resolved 100\% may have had concurrent progression of nontarget lesions.
Patients with baseline target lesion and at least one post-baseline assessment of target lesion are presented (N+P, $n=19)$. (DOCX $177 \mathrm{~kb}$ )

\section{Abbreviations}

AE: adverse event; ALT: alanine aminotransferase; aRCC: advanced or metastatic renal cell carcinoma; AST: aspartate aminotransferase; Cl: confidence interval; DLT: dose-limiting toxicity; DoR: duration of response; MSKCC: Memorial Sloan Kettering Cancer Center; MTD: maximum tolerated dose; mTOR: mammalian target of rapamycin; N + P: nivolumab 2 mg/kg plus pazopanib 800 mg; N + S: nivolumab $2 \mathrm{mg} / \mathrm{kg}$ or $5 \mathrm{mg} / \mathrm{kg}$ plus sunitinib $50 \mathrm{mg}$; N2: nivolumab $2 \mathrm{mg} /$ kg; N5: nivolumab 5 mg/kg; NR: not reached; ORR: objective response rate; OS: overall survival; PD-1: programmed death-1; PFS: progression-free survival; RECIST: Response Evaluation Criteria in Solid Tumors; SD: standard deviation; Select TRAEs: treatment-related adverse events with possible immune-mediated etiology; TRAEs: treatment-related adverse events; TKI: tyrosine kinase inhibitor; VEGF: vascular endothelial growth factor

\section{Acknowledgements}

We thank the patients and their families, as well as the investigators and participating study teams, for making this study possible. We also thank the late Dr. Paul Gagnier (central medical monitor). Professional medical writing and editorial assistance were provided by Jennifer Tyson, PhD, Maria Soushko, PhD, Richard Daniel, PhD, and Lawrence Hargett of PPSI (a PAREXEL company), funded by Bristol-Myers Squibb.

\section{Funding}

This study was sponsored by Bristol-Myers Squibb. Authors received no financial support or compensation for publication of this manuscript.

\section{Availability of data and materials}

Bristol-Myers Squibb policy on data sharing may be found at https:// www.bms.com/researchers-and-partners/independent-research/data-sharingrequest-process.html.

\section{Authors' contributions}

$\mathrm{HJH}$ conceived and designed the study. AA, ERP, MSE, LDL, TMB, DFM, MC, $\mathrm{CK}, \mathrm{BIR}, \mathrm{DYCH}, \mathrm{JK}, \mathrm{MHV}$, JS, and HJH provided patients for the study. All authors collected, reviewed, analyzed and interpreted the data; all authors participated in writing the manuscript, and approved the final version of the manuscript.

\section{Ethics approval and consent to participate}

The CheckMate 016 study was approved by the local site-specific institutional review boards or an independent ethics committee and conducted in accordance with International Conference on Harmonisation Good Clinical Practice guidelines. Written informed consent was obtained from all patients based on Declaration of Helsinki principles before initiation of any study procedures. The trail was registered on Clinicaltrials.gov (NCT01472081) on November 16, 2011.

\section{Consent for publication}

\section{Not applicable.}

\section{Competing interests}

The following represents disclosure information provided by authors of this manuscript.

AA. Honoraria: Bristol-Myers Squibb, Pfizer, Merck, Exelixis. Consulting or Advisory Role: Bristol-Myers Squibb, Merck. Research Funding: Bristol-Myers Squibb, Merck, Dynavax. Travel, Accommodations, Expenses: Bristol-Myers Squibb, Pfizer, Merck, Exelixis. ERP. Consulting or Advisory Role: Bristol-Myers Squibb, Acceleron, Astellas, AstraZeneca, Dendreon, Genentech/Roche, GlaxoSmithKline, Merck, Novartis, Pfizer, Eli Lilly Inc., SynerGene Therapeutics, Inovio, Clovis, Horizon Pharma, Exelixis, Aveo Pharmaceuticals (Inst), BristolMyers Squibb (Inst), Dendreon (Inst), GlaxoSmithKline (Inst), Eli Lilly Inc. (Inst), Merck (Inst), Peloton (Inst), Pfizer (Inst). Research Funding: Bristol-Myers Squibb, Acceleron (Inst), AstraZeneca (Inst). Patents, Royalties, Other Intellectual Property: U.S. Patent Application No. 14/588,503, pending, filed 1/2/2015; US Patent Application No. 15/226,474, pending, filed 7/1/2015. Travel, Accommodations, Expenses: Bristol-Myers Squibb. Other Relationship: BristolMyers Squibb (fees for participating in review activities; for writing or reviewing the manuscript; for providing writing assistance, medicines, equipment, or admin support; development of educational presentations); Merck (fees 
for development of educational presentations); Roche (fees for development of educational presentations); Novartis (fees for development of educational presentations). MSE. Stock ownership (managed account): Bristol-Myers Squibb. LDL. No relationship to disclose. TMB. Employment: Tennessee Oncology, Sarah Cannon Research Institute. Consulting or Advisory Role: Ignyta (Inst), Guardant Health, Loxo, Pfizer, Moderna Therapeutics (Inst). Research Funding: (Inst) Daiichi Sankyo, Medpacto, Inc., Incyte, Mirati Therapeutics, Medlmmune, AbbVie, AstraZeneca, Leap Therapeutics, MabVax, Stemline Therapeutics, Merck, Lilly, GlaxoSmithKline, Novartis, Pfizer, Principa Biopharma, Genentech/Roche, Deciphera, Merrimack, Immunogen, Millennium, Ignyta, Calithera Biosciences, Kolltan Pharmaceuticals, Peleton, Immunocore, Roche, Aileron Therapeutics, Bristol-Myers Squibb, Amgen, Moderna Therapeutics, Sanofi, Boehringer Ingelheim, Astellas Pharma, Five Prime Therapeutics, Jacobio. DFM. Consulting or Advisory Role: Array BioPharma, BristolMyers Squibb, Eisai, Exelixis, Genentech, Merck, Novartis, Pfizer. Research Funding: Prometheus (Inst). MC. Consulting or Advisory Role: AstraZeneca, Merck, Astellas, Medivation. CK. Honoraria: Bristol-Myers Squibb, Pfizer. Consulting or Advisory Role: Bristol-Myers Squibb, Pfizer. BIR. Consulting or Advisory Role: Bristol-Myers Squibb. DYCH. Consulting or Advisory Role: BristolMyers Squibb, Pfizer, Novartis. JK. No relationship to disclose. MHV. Honoraria: Novartis. Consulting or Advisory Role: GlaxoSmithKline, Exelixis, Natera, Calithera, Pfizer. Research Funding: Bristol-Myers Squibb, Roche/Genentech. Travel, Accommodations, Expenses: Takeda, Novartis. JS. Honoraria: Celgene, Lilly. Consulting or Advisory Role: Celgene, Lilly. Research Funding: Celgene, Sanofi, Roche. EB. Employment: Bristol-Myers Squibb. Stock or Other Ownership: Bristol-Myers Squibb. LY. Employment: Bristol-Myers Squibb, at the time the study was performed. Stock or Other Ownership: Bristol-Myers Squibb, at the time the study was performed. $\mathrm{HJH}$. Consulting or Advisory Role: BristolMyers Squibb, Pfizer, Exelixis. Research Funding: Bristol-Myers Squibb. Travel, Accommodations, Expenses: Bristol-Myers Squibb, Pfizer, Exelixis.

\section{Publisher's Note}

Springer Nature remains neutral with regard to jurisdictional claims in published maps and institutional affiliations.

\section{Author details}

${ }^{1}$ Immunotherapy program, Levine Cancer Institute, Carolinas HealthCare System, 1024 Morehead Medical Drive, Charlotte, NC 28204, USA. ${ }^{2}$ Division of Genitourinary Medical Oncology, Department of Hematology/Oncology, Fox Chase Cancer Center, Philadelphia, PA 19111, USA. ${ }^{3}$ Division of Oncology, Department of Medicine, Roswell Park Cancer Institute, Elm and Carlton Streets, Buffalo, NY 14203, USA. ${ }^{4}$ Department of Medicine at The Geisel School of Medicine and The Norris Cotton Cancer Center at Dartmouth-Hitchcock Medical Center, Lebanon, NH 03756, USA. ${ }^{5}$ Sarah Cannon Research Institute/Tennessee Oncology, PLLC, Nashville, TN 37203, USA. ${ }^{6}$ Department of Medicine, Beth Israel Deaconess Medical Center, Dana-Farber/Harvard Cancer Center, Boston, MA 02215, USA. ${ }^{7}$ Department of Oncology, Johns Hopkins Sidney Kimmel Comprehensive Cancer Center, Baltimore, MD 21287, USA. ${ }^{8}$ Division of Medical Oncology, British Columbia Cancer Agency, Vancouver, BC V5Z 4E6, Canada. ' Lerner College of Medicine, Department of Hematology and Oncology, Cleveland Clinic Taussig Cancer Institute, Cleveland, $\mathrm{OH}$ 44195, USA. ${ }^{10}$ Department of Oncology, Tom Baker Cancer Center, University of Calgary, Calgary, AB T2N 4N2, Canada. ${ }^{11}$ Cancer Clinical Research Unit (CCRU), Princess Margaret Cancer Centre, Toronto, ON M5G 1Z5, Canada. ${ }^{12}$ Department of Medicine, Memorial Sloan Kettering Cancer Center, New York, NY 10065, USA. ${ }^{13}$ Department of Oncology, Cross Cancer Institute, University of Alberta, Edmonton, AB T6G 1Z2, Canada. ${ }^{14}$ Oncology - Global Clinical Research, Bristol-Myers Squibb, Princeton, NJ 08541, USA. ${ }^{15}$ Department of Internal Medicine, UT Southwestern - Kidney Cancer Program, Dallas, TX 75390, USA.
\end{abstract}

\section{Received: 5 July 2018 Accepted: 26 September 2018}

\section{Published online: 22 October 2018}

\section{References}

1. Choueiri TK, Escudier B, Powles T, Tannir NM, Mainwaring PN, Rini BI, et al. Cabozantinib versus everolimus in advanced renal cell carcinoma (METEOR): final results from a randomised, open-label, phase 3 trial. Lancet Oncol. 2016;17(7):917-27.
2. Choueiri TK, Fishman MN, Escudier B, McDermott DF, Drake CG, Kluger H, et al. Immunomodulatory activity of nivolumab in metastatic renal cell carcinoma. Clin Cancer Res. 2016;22(22):5461-71.

3. Choueiri TK, Halabi S, Sanford BL, Hahn O, Michaelson MD, Walsh MK, et al. Cabozantinib versus sunitinib as initial targeted therapy for patients with metastatic renal cell carcinoma of poor or intermediate risk: the Alliance A031203 CABOSUN trial. J Clin Oncol. 2017;35(6):591-7.

4. Escudier B, Eisen T, Stadler WM, Szczylik C, Oudard S, Staehler M, et al. Sorafenib for treatment of renal cell carcinoma: final efficacy and safety results of the phase III treatment approaches in renal cancer global evaluation trial. J Clin Oncol. 2009;27(20):3312-8.

5. Hutson TE, Lesovoy V, Al-Shukri S, Stus VP, Lipatov ON, Bair AH, et al. Axitinib versus sorafenib as first-line therapy in patients with metastatic renal-cell carcinoma: a randomised open-label phase 3 trial. Lancet Oncol. 2013;14(13):1287-94.

6. McDermott DF, Drake CG, Sznol M, Choueiri TK, Powderly JD, Smith DC, et al. Survival, durable response, and long-term safety in patients with previously treated advanced renal cell carcinoma receiving nivolumab. J Clin Oncol. 2015;33(18):2013-20.

7. Motzer RJ, Escudier B, McDermott DF, George S, Hammers HJ, Srinivas S, et al. Nivolumab versus everolimus in advanced renal-cell carcinoma. N Engl J Med. 2015;373(19):1803-13.

8. Motzer RJ, Hutson TE, Cella D, Reeves J, Hawkins R, Guo J, et al. Pazopanib versus sunitinib in metastatic renal-cell carcinoma. $\mathrm{N}$ Engl J Med. 2013;369(8):722-31.

9. Motzer RJ, Hutson TE, Tomczak P, Michaelson MD, Bukowski RM, Oudard S, et al. Overall survival and updated results for sunitinib compared with interferon alfa in patients with metastatic renal cell carcinoma. J Clin Oncol. 2009;27(22):3584-90.

10. Motzer RJ, Rini BI, Bukowski RM, Curti BD, George DJ, Hudes GR, et al. Sunitinib in patients with metastatic renal cell carcinoma. JAMA. 2006; 295(21):2516-24.

11. Sternberg CN, Davis ID, Mardiak J, Szczylik C, Lee E, Wagstaff J, et al. Pazopanib in locally advanced or metastatic renal cell carcinoma: results of a randomized phase III trial. J Clin Oncol. 2010;28(6):1061-8.

12. Sternberg CN, Hawkins RE, Wagstaff J, Salman P, Mardiak J, Barrios $\mathrm{CH}$, et al. A randomised, double-blind phase III study of pazopanib in patients with advanced and/or metastatic renal cell carcinoma: final overall survival results and safety update. Eur J Cancer. 2013;49(6): 1287-96.

13. Motzer RJ, Rini BI, McDermott DF, Redman BG, Kuzel TM, Harrison MR, et al. Nivolumab for metastatic renal cell carcinoma: results of a randomized phase II trial. J Clin Oncol. 2015;33(13):1430-7.

14. Schmid TA, Gore ME. Sunitinib in the treatment of metastatic renal cell carcinoma. Ther Adv Urol. 2016;8(6):348-71.

15. Cella D, Beaumont JL. Pazopanib in the treatment of advanced renal cell carcinoma. Ther Adv Urol. 2016;8(1):61-9.

16. Motzer RJ, Hutson TE, McCann L, Deen K, Choueiri TK. Overall survival in renal-cell carcinoma with pazopanib versus sunitinib. N Engl J Med. 2014; 370(18):1769-70.

17. Susman E. Pazopanib or sunitinib in metastatic renal cancer: Outcomes are similar. Oncology Times. 2016;38(6):17.

18. Morales JMR, Wells JC, Donskov F, Bjarnason GA, Lee JL, Knox JJ, et al. Firstline sunitinib versus pazopanib in metastatic renal cell carcinoma (mRCC): Results from the International Metastatic Renal Cell Carcinoma Database Consortium (IMDC). J Clin Oncol. 2016;34(suppl 2S):Abstract 544.

19. Gore ME, Szczylik C, Porta C, Bracarda S, Bjarnason GA, Oudard S, et al. Final results from the large sunitinib global expanded-access trial in metastatic renal cell carcinoma. Br J Cancer. 2015;113(1):12-9.

20. Dong Y, Sun Q, Zhang X. PD-1 and its ligands are important immune checkpoints in cancer. Oncotarget. 2017;8(2):2171-86.

21. $\mathrm{OPDIVO}^{\circledR}$ (nivolumab) injection [prescribing information]. Bristol-Myers Squibb: Princeton, NJ; 2018.

22. European Medicines Agency. European public assessment report (EPAR) for Opdivo. http://www.ema.europa.eu/ema/index.jsp?curl=/pages/medicines/ human/medicines/003985/human_med_001876.jsp\&mid= WC0b01ac058001d124. Accessed November 7, 2017.

23. Hammers HJ, Plimack ER, Infante JR, Rini BI, McDermott DF, Lewis LD, et al. Safety and efficacy of nivolumab in combination with ipilimumab in metastatic renal cell carcinoma: the CheckMate 016 study. J Clin Oncol. 2017:35(34):3851-8. 
24. Motzer RJ, Tannir NM, McDermott DF, Aren Frontera O, Melichar B, Choueiri TK, et al. Nivolumab plus ipilimumab versus sunitinib in advanced renal-cell carcinoma. N Engl J Med. 2018;378(14):1277-90.

25. Ko JS, Zea AH, Rini BI, Ireland JL, Elson P, Cohen $\mathrm{P}$, et al. Sunitinib mediates reversal of myeloid-derived suppressor cell accumulation in renal cell carcinoma patients. Clin Cancer Res. 2009;15(6):2148-57.

26. Hughes PE, Caenepeel S, Wu LC. Targeted therapy and checkpoint immunotherapy combinations for the treatment of cancer. Trends Immunol. 2016;37(7):462-76.

27. Atkins MB, Plimack ER, Puzanov I, Fishman MN, McDermott DF, Cho DC, et al. Axitinib in combination with pembrolizumab in patients with advanced renal cell cancer: a non-randomised, open-label, dose-finding, and dose-expansion phase 1b trial. Lancet Oncol. 2018;19(3):405-15.

28. Lee C, Makker V, Rasco D, Taylor M, Dutcus C, Shumaker R, et al. A phase $1 \mathrm{~b} / 2$ trial of lenvatinib plus pembrolizumab in patients with renal cell carcinoma. Ann Oncol. 2017;28(suppl 5):Abstract 8470.

29. Chowdhury S, McDermott DF, Voss MH, Hawkins RE, Aimone P, Voi M, et al. A phase $1 / I I$ study to assess the safety and efficacy of pazopanib (PAZ) and pembrolizumab (PEM) in patients (pts) with advanced renal cell carcinoma (aRCC). J Clin Oncol. 2017;35(suppl):Abstract 4506.

30. Ji Y, Liu P, Li Y, Bekele BN. A modified toxicity probability interval method for dose-finding trials. Clin Trials. 2010;7(6):653-63.

31. Amin A, Plimack ER, Infante JR, Ernstoff M, Rini BI, McDermott DF, et al. Nivolumab (anti-PD-1; BMS-936558, ONO-4538) in combination with sunitinib (S) or pazopanib (P) in patients (pts) with metastatic renal cell carcinoma (mRCC). Ann Oncol. 2014;25(suppl 4):Abstract 1052PD.

32. Porta C, Gore ME, Rini Bl, Escudier B, Hariharan S, Charles LP, et al. Long-term safety of sunitinib in metastatic renal cell carcinoma. Eur Urol. 2016;69(2):345-51.

33. Postow MA, Chesney J, Pavlick AC, Robert C, Grossmann K, McDermott D, et al. Nivolumab and ipilimumab versus ipilimumab in untreated melanoma. N Engl J Med. 2015;372(21):2006-17.

34. Robert C, Ribas A, Hamid O, Daud A, Wolchok JD, Joshua AM, et al. Durable complete response after discontinuation of pembrolizumab in patients with metastatic melanoma. J Clin Oncol. 2018:36(17):1668-74.

35. Kaufman HL, Russell JS, Hamid O, Bhatia S, Terheyden P, D'Angelo SP, et al. Updated efficacy of avelumab in patients with previously treated metastatic Merkel cell carcinoma after $\geq 1$ year of follow-up: JAVELIN Merkel 200, a phase 2 clinical trial. J Immunother Cancer. 2018;6(1):7.

36. Petrylak DP, Powles T, Bellmunt J, Braiteh F, Loriot $Y$, Morales-Barrera $R$, et al. Atezolizumab (MPDL3280A) monotherapy for patients with metastatic urothelial cancer: long-term outcomes from a phase 1 study. JAMA Oncol. 2018;4(4):537-44.

37. Choueiri TK, Larkin J, Oya M, Thistlethwaite F, Martignoni M, Nathan P, et al. Preliminary results for avelumab plus axitinib as first-line therapy in patients with advanced clear-cell renal-cell carcinoma (JAVELIN renal 100): an open-label, dosefinding and dose-expansion, phase 1b trial. Lancet Oncol. 2018;19(4):451-60.

38. Atkins MB, McDermott DF, Powles $P$, Motzer RJ, Rini BI, Fong $L$, et al. IMmotion150: A phase II trial in untreated metastatic renal cell carcinoma (mRCC) patients (pts) of atezolizumab (atezo) and bevacizumab (bev) vs and following atezo or sunitinib (sun). J Clin Oncol. 2017;35(15 suppl):Abstract 4505.

39. Motzer RJ, Powles T, Atkins MB, Escudier B, McDermott DF, Suarez C, et al. IMmotion151: A randomized phase III study of atezolizumab plus bevacizumab vs sunitinib in untreated metastatic renal cell carcinoma (mRCC). J Clin Oncol. 2018;36(6 suppl):Abstract 578.

40. Rini BI, Powles T, Chen M, Puhlmann M, Atkins MB. Phase 3 KEYNOTE-426 trial: Pembrolizumab (pembro) plus axitinib versus sunitinib alone in treatment-naive advanced/metastatic renal cell carcinoma (mRCC). J Clin Oncol. 2017;35(suppl):Abstract TPS4597.

41. Choueiri TK, Rini Bl, Larkin JMG, Bjarnason GA, Gravis G, Gurney H, et al. Avelumab plus axitinib vs sunitinib as first-line treatment of advanced renal cell carcinoma: Phase 3 study (JAVELIN Renal 101). J Clin Oncol. 2017; 35(suppl):Abstract TPS4594.

42. Motzer RJ, Grunwald V, Hutson TE, Porta C, Powles T, Eto M, et al. A phase III trial to compare efficacy and safety of lenvatinib in combination with everolimus or pembrolizumab vs sunitinib alone in first-line treatment of patients (Pts) with metastatic renal cell carcinoma (RCC). J Clin Oncol. 2017; 35(suppl):Abstract TPS4595.

43. Choueiri TK, Apolo AB, Powles T, Escudier B, Aren OR, Shah A, et al. A phase 3, randomized, open-label study of nivolumab combined with cabozantinib vs sunitinib in patients with previously untreated advanced or metastatic renal cell carcinoma (RCC; CheckMate 9ER). J Clin Oncol. 2018;36(suppl):Abstract TPS4598.

Ready to submit your research? Choose BMC and benefit from:

- fast, convenient online submission

- thorough peer review by experienced researchers in your field

- rapid publication on acceptance

- support for research data, including large and complex data types

- gold Open Access which fosters wider collaboration and increased citations

- maximum visibility for your research: over $100 \mathrm{M}$ website views per year

At $\mathrm{BMC}$, research is always in progress.

Learn more biomedcentral.com/submissions 